\title{
The association of chronic obstructive pulmonary disease, disability, engagement in social activities, and mortality among US adults aged 70 years or older, 1994-2006
}

\author{
This article was published in the following Dove Press journal: \\ International Journal of COPD \\ 15 January 2014 \\ Number of times this article has been viewed
}

\author{
Yong Liu' \\ Janet B Croft ${ }^{\prime}$ \\ Lynda A Anderson ${ }^{2}$ \\ Anne G Wheaton' \\ Letitia R Presley-Cantrell ${ }^{3}$ \\ Earl S Ford' \\ 'Epidemiology and Surveillance \\ Branch, ${ }^{2}$ Healthy Aging Program, \\ Division of Population Health, \\ CDC and Rollins School of Public \\ Health, Emory University, ${ }^{3}$ Program \\ Development and Services \\ Management, Division of Heart \\ Disease and Stroke Prevention, \\ Centers for Disease Control and \\ Prevention, Atlanta, GA, USA
}

Correspondence: Yong Liu Epidemiology and Surveillance Branch, Division of Population Health, Centers for Disease Control and Prevention, 4770 Buford Highway Northeast, Mailstop F-78, Atlanta, GA 3034I, USA

Tel +I 7704885528

Fax +I 7704885965

Email ikd8@cdc.gov
Purpose: To assess associations among chronic obstructive pulmonary disease (COPD), disability as measured by activities of daily living (ADL) and instrumental ADL (IADL), engagement in social activities, and death among elderly noninstitutionalized US residents.

Materials and methods: A nationally representative sample of 9,415 adults who were aged $\geq 70$ years and responded to the Second Supplement on Aging survey in 1994-1996 and mortality follow-up study through 2006 were assessed. Multiple logistic regression analyses were performed to assess the risk of all-cause mortality in participants with COPD after accounting for age, sex, race/ethnicity, and smoking status.

Results: At baseline, approximately $9.6 \%$ of study participants reported having COPD. Compared with participants without COPD, those with COPD were significantly more likely $(P<0.05)$ to have difficulty with at least one ADL (44.3\% versus [vs] 27.5\%) and with at least one IADL ( $59.9 \%$ vs $40.2 \%)$, significantly less likely to be engaged in social activities ( $32.6 \% \mathrm{vs} 26.3 \%)$, and significantly more likely to die by 2006 ( $70.7 \%$ vs $60.4 \%$; adjusted risk ratio $1.15, P<0.05)$. The association between COPD and risk for death was moderately attenuated by disability status.

Conclusion: COPD is positively associated with disability and mortality risk among US adults aged $\geq 70$ years. The significant relationship between COPD and mortality risk was moderately attenuated, but was not completely explained by stages of ADL and IADL limitations and social activities.

Keywords: chronic obstructive pulmonary disease, mortality, activities of daily living, instrumental activities of daily living, disability

\section{Introduction}

Chronic lower respiratory diseases have been the third leading cause of death since 2008 in the US. ${ }^{1,2}$ The most common chronic lower respiratory disease is chronic obstructive pulmonary disease (COPD), which is characterized by chronic airflow obstruction, and at least $75 \%$ of COPD-related deaths in the US have been attributed to smoking. ${ }^{3,4}$ However, although the prevalence of current smoking among US adults declined from $24.0 \%$ in 2000 to $19.6 \%$ in 2010 , the COPD death rate did not decline as rapidly as the death rates from heart disease, cancer, or all causes. ${ }^{5,6}$ Furthermore, a four-decade secular decline in the overall mortality rate among US adults has been much slower among those with COPD than among those with normal lung function. ${ }^{7}$

A recent report from the Global initiative for chronic Obstructive Lung Disease suggests that COPD progression, which results from dyspnea, fatigue, inactivity, 
deconditioning, and aging, may help explain this relatively static trend in the COPD mortality rate. ${ }^{8}$ Because the ability of people with COPD to perform daily activities necessary for independent living declines as their COPD progresses, they are more likely to experience disability, ${ }^{9,10}$ and as a result are at greater risk for social restriction and depression. ${ }^{11-13}$ Furthermore, those people with exacerbated COPD could be more likely to have comorbidities, and have increased risk for death due to the interrelated effects of disability and mental distress. ${ }^{14-17}$

Reflecting the public health challenges posed by COPD, Healthy People 2020 has proposed five COPD-related objectives, including one that focuses on reducing activity limitations among adults with COPD. ${ }^{18}$ However, a lack of consensus regarding the definition of disability has made it difficult to measure and compare across studies and over time. ${ }^{19}$ Two of the most frequently used measures of disability are limitations in activities of daily living (ADL) $)^{20,21}$ and limitations in instrumental ADL (IADL), which are more complex activities than ADL. ${ }^{22}$ Both ADL and IADL limitations were used to measure disability among respondents to the Supplement on Aging (SOA) of the National Health Interview Survey (NHIS) in 1984-1986 and 1994-1996. ${ }^{23}$ In addition, research demonstrated that modified disability measures of ADL- and IADL-limitation stages had more specific clinical meanings related to secondary prevention of chronic conditions than did simple counts of ADL or IADL difficulties, and ADL stages were associated with mortality over time. ${ }^{24-26}$

In this study, we assessed the relationships between COPD and disability (measured by stages of ADL and IADL limitations), social activities, and death among noninstitutionalized US adults aged 70 years or older and also whether disability and social activities attenuated the relationship between COPD and death.

\section{Materials and methods Data sources}

Baseline data for this study were obtained from the Second SOA (SOA II) in the 1994-1996 NHIS, a national survey of civilian noninstitutionalized US adults who were selected through a multistage sampling process. Participation in SOA II was restricted to NHIS participants aged 70 years or older (information available at http://www.cdc.gov/nchs/lsoa/soa2. htm). To ascertain SOA II participants' survival status as of December 31, 2006, the National Death Index (NDI) database as well as data collected during follow-up interviews conducted in 1997-1998 or 1999-2000 as part of the Second
Longitudinal SOA (LSOA II) was applied. Information about the NDI and LSOA II is available on the Centers for Disease Control and Prevention website. ${ }^{27}$ The 1994-1996 NHIS and LSOA II study were approved by the Research Review Board of the National Center for Health Statistics, Centers for Disease Control and Prevention.

SOA II surveyed 9,447 respondents with a mean age of 77.3 ( standard error $=0.2$ ) years and an overall response rate of $87.4 \%$ (http://www.cdc.gov/nchs/lsoa/soa2.htm). After excluding respondents who either had not been tracked for survival status as of December 31, 2006 or had missing values on selected sociodemographics, COPD status, and social activity at baseline, 9,415 respondents $(99.7 \%)$ were available for this study.

\section{Variables}

Exposure variables were COPD status, stage of ADL limitation, stage of IADL limitation, and social activity status. Respondents' COPD status was based on their affirmative response to the question: "Did a doctor ever tell you that you had chronic bronchitis or emphysema?"

Respondents' ADL-limitation stage was based on difficulties in performing seven ADL, which were assessed by the questions: "By yourself and without using special equipment, how much difficulty do you have a) bathing/showering; b) dressing; c) eating; d) getting in or out of bed or chair; e) walking; f) getting outside; and g) using the toilet, including getting to the toilet?" Response options ranged from no difficulty (0) to unable to perform (3). Consistent with the International Classification of Functioning, Disability, and Health, ${ }^{28}$ an index of five ADL stages (ADL 0, no difficulty; ADL I, mild difficulty; ADL II, moderate difficulty; ADL III, severe difficulty; and ADL IV, complete difficulty) were constructed to reflect respondents' difficulties with ADL. ${ }^{24,29}$ In our analyses, we combined stages III and IV to obtain adequate statistical power.

Respondents' IADL-limitation stage was based on difficulties in the ability to perform six IADL, which were assessed through the questions: "By yourself, how much difficulty do you have a) preparing your own meals; b) shopping for groceries and personal items, such as toilet items or medicines; c) managing your money, such as keeping track of expenses or paying bills; d) using the telephone; e) doing heavy housework, like scrubbing floors, or washing windows; f) doing light housework, like doing dishes, straightening up, or light cleaning?" Response options again ranged from no difficulty ( 0 ) to unable to perform (3), and five stages of IADL difficulty were based on Stineman et al's definition. ${ }^{25}$ As done for the ADL-limitation stage, 
we combined stages III and IV to obtain adequate statistical power. The ADL and IADL indices have been widely utilized to address disability status, ${ }^{24-26,29-31}$ although they have not been validated so far.

Respondents' social activities were based on their response to the following multiple questions: "During the past 2 weeks, did you a) get together socially with friends or neighbors, b) talk with friends or neighbors on the telephone, c) get together with any relatives, not including those living with you, d) talk with any relatives on the telephone, not including those living with you, e) go to church, temple, or another place of worship for services or other activities, f) go to a show or movie, sports event, club meeting, class, or other group event, and g) go out to eat at a restaurant?" Respondents were given one point for each positive response; possible social activity index scores thus ranged from 0 to 7 . We constructed a social activity index in which a score of 6 or 7 was classified as high social activity, 4 or 5 as medium social activity, and $0-3$ as low social activity. The SOA II social activity questions were widely utilized in previous studies. ${ }^{30,31}$

The covariates in our analyses were age (70-74, 75-79, or $\geq 80$ years), sex, race (white or nonwhite), and smoking status (current smokers, smoked $\geq 100$ cigarettes in lifetime and current smoking every day or some days; former smokers, smoked $\geq 100$ cigarettes in lifetime but were not smoking now; and those who had never smoked).

\section{Statistical analyses}

Our first step was to assess the weighted distributions of all selected characteristics in the study population, both overall and by COPD status. We then assessed the unadjusted cumulative incidence (deaths per 100 respondents) and incidence rate (deaths per 1,000 person-years) through 2006 for groups defined by each selected characteristic. Using two multiple logistic regression models, an initial model that controlled for the selected covariates and a final model that controlled for all the selected characteristics, we calculated risk ratios (RRs) and 95\% confidence intervals (CIs) for the relationships between each selected characteristic and the likelihood of dying from any cause among respondents through the end of 2006. We used multiple logistic regression analyses because of violations of the Cox proportional hazard assumption (Schoenfeld residual). Finally, we used a modified Sobel test tailored for a dichotomous outcome variable to assess whether the relationship between COPD status and risk of dying was attenuated by social activities or the stage of ADL or IADL difficulties. ${ }^{32,33}$ The standardized coefficients and the percentage of the total effect from a single mediator were then calculated using a multiple logistic regression models that controlled for covariates. A significant mediating effect was only confirmed if COPD status was significantly associated with both the mediator and risk of death, and the mediator was significantly associated with risk of death. ${ }^{34}$ Furthermore, a partial mediating effect was determined if the relationship between COPD and mortality remained significant when the potential mediator was added into the model, and so was a complete mediating effect if the relationship between COPD and mortality was no longer significant with the mediator in the model. ${ }^{34} \mathrm{SAS}$-callable SUDAAN (version 10.0.1; Research Triangle Institute, Research Triangle Park, NC, USA) was used in all analyses to account for the complex sampling design.

\section{Results}

\section{Characteristics of participants at baseline}

Of the 9,415 survey participants in our study, 59.8\% were women, $60.5 \%$ were aged $\geq 75$ years, $89.9 \%$ were white, and $48.0 \%$ were former or current smokers, $29.1 \%$ had at least one difficulty with functional ADL, $42.1 \%$ had at least one difficulty with IADL, and $26.9 \%$ had a low level of social activities during the previous 2 weeks. Among baseline study participants, 9.6\% (95\% CI $=8.9-10.3)$ reported having COPD. COPD prevalence did not differ significantly by sex or age, but was significantly higher among white participants than nonwhite participants (10.0\% versus [vs] 5.7\%), and among current smokers (18.1\%) and former smokers (12.8\%) than among those never having smoked (5.8\%).

Although there were no differences in sex or age groups by COPD status, respondents with COPD were more likely to be white (Table $1,94.0 \%$ vs $89.4 \%$ ), a former smoker (50.6\% vs $36.7 \%)$, a current smoker $(18.5 \%$ vs $9.0 \%$, $P<0.001)$, and have low (0-3) social activities in the previous 2 weeks (32.6\% vs 26.3\%) than respondents without COPD $(P<0.05)$. Participants with COPD were less likely than those without COPD to report no functional ADL difficulties $(55.7 \%$ vs $72.5 \%)$ and no IADL difficulties $(40.1 \%$ vs $59.8 \%)(P<0.05)$. Persons with COPD compared to those without had significantly greater percentage of persons at higher ADL and IADL stages $(P<0.05)$.

Respondents with COPD were significantly more likely to report having any difficulty with each individual ADL and with most IADL than those without COPD (Figure 1A and $\mathrm{B}, P<0.05)$. They were also significantly less likely to report engaging in four social activities during the previous 2 weeks: getting together with friends or neighbors, going 
Table I Baseline distributions of selected characteristics among survey participants, by COPD ${ }^{\text {a }}$ status: the Second Supplement on Aging, National Health Interview Survey, 1994-1996

\begin{tabular}{|c|c|c|c|c|c|c|}
\hline \multirow[t]{2}{*}{ Baseline characteristic } & \multicolumn{2}{|l|}{ Total } & \multicolumn{2}{|c|}{ COPD } & \multicolumn{2}{|c|}{ No COPD } \\
\hline & $n^{b}$ & $\%(95 \% \mathrm{Cl})^{c}$ & $\mathrm{n}^{\mathrm{b}}$ & $\%(95 \% \mathrm{Cl})^{c}$ & $\mathbf{n}^{\mathrm{b}}$ & $\%(95 \% \mathrm{Cl})^{c}$ \\
\hline Total & 9,415 & & 883 & & 8,532 & \\
\hline \multicolumn{7}{|l|}{ Sex } \\
\hline Men & 3,736 & $40.2(39.3-4 I .1)$ & 350 & $39.8(36.1-43.5)$ & 3,386 & $40.2(39.3-4 I .1)$ \\
\hline Women & 5,679 & $59.8(58.9-60.7)$ & 533 & $60.2(56.5-63.9)$ & 5,146 & $59.8(58.9-60.7)$ \\
\hline \multicolumn{7}{|l|}{ Age, years } \\
\hline $70-74$ & 3,651 & $39.5(38.3-40.6)$ & 353 & $39.9(36.9-42.9)$ & 3,298 & $39.4(38.2-40.6)$ \\
\hline $75-79$ & 2,742 & $29.2(28.3-30.1)$ & 275 & $32.0(28.7-35.3)$ & 2,467 & $28.9(27.9-29.8)$ \\
\hline$\geq 80$ & 3,022 & $31.4(30.2-32.5)$ & 255 & $28.1(25.0-31.1)$ & 2,767 & $31.7(30.5-32.9)$ \\
\hline \multicolumn{7}{|l|}{ Race/ethnicity } \\
\hline White & 8,205 & $89.9(88.6-91.1)$ & 814 & $94.0(92.4-95.6)$ & 7,391 & $89.4(88 . I-90.7)$ \\
\hline Nonwhite & 1,210 & $10.1(8.9-11.4)$ & 69 & $6.0(4.4-7.6)$ & $|| 4 \mid$, & $10.6(9.3-11.9)$ \\
\hline \multicolumn{7}{|l|}{ Smoking status } \\
\hline Never smoked & 4,886 & $52.0(50.7-53.3)$ & 277 & $30.9(27.5-34.4)$ & 4,609 & $54.3(52.9-55.6)$ \\
\hline Former smoker & 3,418 & $38.1(36.8-39.3)$ & 437 & $50.6(46.7-54.4)$ & 2,981 & $36.7(35.4-38.0)$ \\
\hline Current smoker & 923 & $9.9(9.2-10.6)$ & 162 & $18.5(|5.8-2| . \mid)$ & 761 & $9.0(8.3-9.7)$ \\
\hline \multicolumn{7}{|l|}{ Stage of ADL limitations ${ }^{d}$} \\
\hline 0 & 6,607 & $70.9(69.7-72.1)$ & 481 & $55.7(52.3-59.2)$ & 6,126 & $72.5(71.3-73.8)$ \\
\hline I & 1,397 & $14.7(13.8-15.6)$ & 201 & $22.5(19.6-25.5)$ & 1,196 & $13.9(13.0-14.8)$ \\
\hline ॥ & 670 & $7.1(6.5-7.7)$ & 88 & $9.7(7.7-11.7)$ & 582 & $6.8(6.1-7.5)$ \\
\hline III or IV & 703 & $7.3(6.6-8.0)$ & 110 & $12.0(9.8-14.3)$ & 593 & $6.8(6.1-7.5)$ \\
\hline \multicolumn{7}{|l|}{ Stage of IADL limitations $\mathrm{s}^{\mathrm{e}}$} \\
\hline 0 & 5,168 & $57.9(56.5-59.4)$ & 332 & $40.1(36.4-43.9)$ & 4,836 & $59.8(58.3-61.3)$ \\
\hline I & I,97| & $21.8(20.8-22.8)$ & 255 & $31.4(27.8-34.9)$ & 1,716 & $20.8(19.8-21.8)$ \\
\hline$\|$ & 1,119 & $12.3(11.4-13.2)$ & 161 & $18.9(\mid 6.1-21.7)$ & 958 & $11.6(10.7-12.6)$ \\
\hline III or IV & 730 & $7.9(7.3-8.6)$ & 85 & $9.6(7.6-11.6)$ & 645 & $7.7(7.0-8.5)$ \\
\hline \multicolumn{7}{|l|}{ Level of social activity $f^{f}$} \\
\hline Low $(0-3)$ & 2,569 & $26.9(25.7-28.1)$ & 294 & $32.6(29.3-35.8)$ & 2,275 & $26.3(25.0-27.6)$ \\
\hline Medium (4-5) & 3,661 & $38.5(37.4-39.7)$ & 350 & $39.0(35.7-42.2)$ & 3,311 & $38.5(37.3-39.7)$ \\
\hline High (6-7) & 3,185 & $34.6(33.2-35.9)$ & 239 & $28.5(25.2-31.7)$ & 2,946 & $35.2(33.8-36.6)$ \\
\hline
\end{tabular}

Notes: ${ }^{2}$ Chronic obstructive pulmonary disease (COPD); bunweighted sample size; ' $w e i g h t e d$ percentage and $95 \%$ confidence interval (Cl) were derived using sample weights; 'stages of functional activities of daily living (ADL) limitations were based on participant's response to six questions about his/her difficulty in bathing/showering, dressing, eating, getting in or out of bed or chairs, walking, and using or getting to the toilet; 'stages of instrumental activities of daily living (IADL) limitations were based on participant's response to six questions about his/her difficulty in preparing meals, shopping, managing money, using the telephone, doing light housework, and doing heavy housework; 'level of social activity was derived from a social activities index score, which was based on participant's responses to multiple questions about his/her participation in the following activities during the previous 2 weeks - getting together with friends or neighbors; talking on the telephone with friends or neighbors; getting together with relatives; talking on the telephone with relatives; going to church, temple, or other place of worship; going to a show or movie, sports events, club meeting, class, or other group event; or going out to eat at a restaurant.

out, eating at a restaurant, going to a place of worship, and going to a group event (Figure 2).

\section{Cumulative incidence of deaths and incidence of deaths per I,000 person-years}

During follow-up from 1994-1996 through 2006, 5,790 of the original survey participants died (61.4\%, 95\% CI 60.1-62.6). Results from fully adjusted logistic regression analyses showed that mortality risk was significantly higher among men than among women, significantly higher among those aged 75 years or older than among those aged 70-74 years, and significantly higher among current and former smokers than among those who had never smoked (Table 2, $P<0.001$ ).
Similar patterns were observed in terms of incidence of deaths per 1,000 person-years.

The mortality risk with adjustment for age, sex, race/ ethnicity, and smoking status increased with stage of ADL difficulties $(P<0.001)$ and stage of IADL difficulties $(P<0.001)$, and declined with level of engagement in multiple social activities $(P<0.001)$. Mortality risk was higher among those with baseline COPD than among those without $(70.7 \%$ vs $60.4 \%, P<0.05$; adjusted RR $=1.15$, 95\% CI 1.09-1.21, Table 2, Model 1). After adjustment for all variables in our multiple logistic regression model, sex, age, smoking status, ADL stages, IADL stages, and level of social activity remained significantly associated with mortality risk (Table 2, Model 2; Figure 3). However, COPD was 


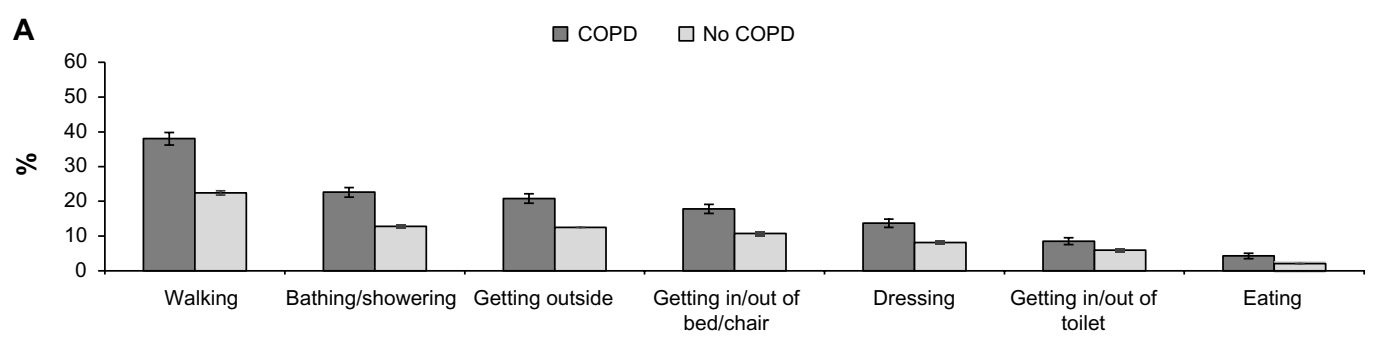

B

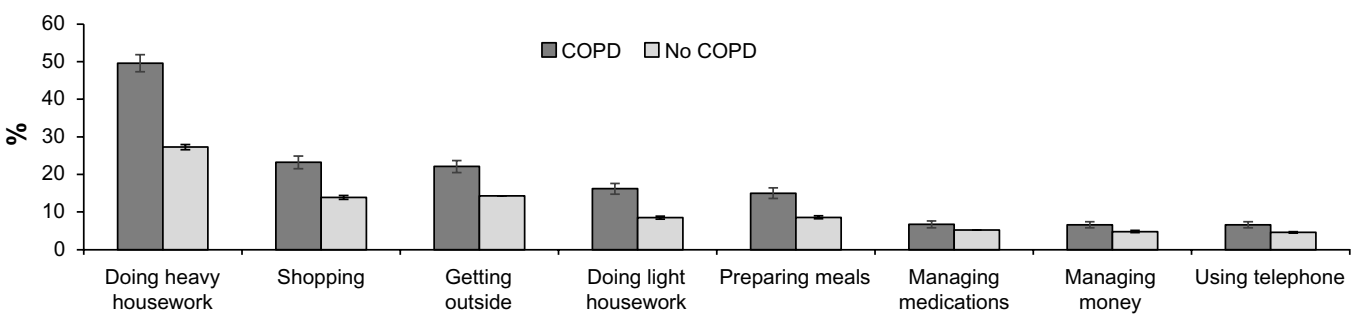

Figure I Age-adjusted percentage and 95\% confidence intervals of any difficulty of activities of daily living (A) and instrumental activities of daily living (B) among survey respondents aged 70 years or older, by chronic obstructive pulmonary disease (COPD) status: the Second Supplement on Aging, $1994-1996$.

associated with higher mortality risk among participants classified as having no difficulty, mild difficulty, or moderate difficulty with ADL $(P<0.05)$, but not among those classified as having severe difficulty or complete difficulty with ADL (Figure 3A). Similarly, COPD was associated with mortality risk only among participants classified as having no difficulty or moderate difficulty with IADL, but not among those classified as having mild, severe, or complete difficulty with IADL (Figure 3B). In contrast, the level of engagement in social activities was positively associated with the risk of COPD-related mortality (data not shown).

\section{Mediation effects of ADL, IADL, and level of social activities}

Results from the Sobel test indicated that the relationship between participants' COPD status and their mortality risk through 2006 was moderately attenuated by their ADL-difficulty stage (indirect effect [IE] =39.7\%) and their IADL difficulty stage (IE $=41.8 \%$ ), and slightly attenuated by their level of social activity (IE $=11.0 \%$ ).

\section{Discussion}

Consistent with findings from a study in Finland, ${ }^{10}$ our results showed that community-dwelling older adults with COPD were more likely to report having ADL and IADL difficulties and less likely to report participating in social activities than those without COPD. These findings also supported previous study results that COPD reduced the functional capacity of COPD patients and their ability to perform daily activities involving the upper and lower extremities. ${ }^{35,36}$

Our finding that mortality risk was associated with partial ADL difficulty but not with complete ADL difficulty among

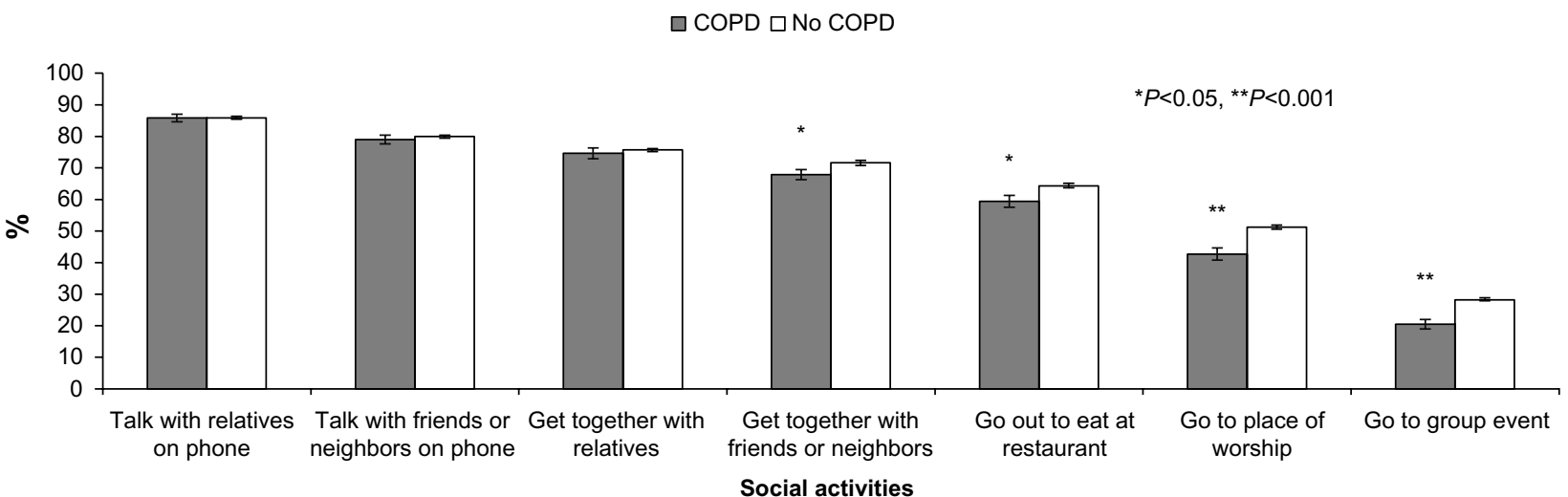

Figure 2 Age-adjusted percentage and $95 \%$ confidence intervals of any engagement in selected social activities during the previous 2 weeks among survey respondents aged 70 years or older, by chronic obstructive pulmonary disease (COPD) status: the Second Supplement on Aging, $1994-1996$. 
Table 2 Cumulative incidence of deaths and incidence of deaths per 1,000 person-years through December 31, 2006 among 9,4I5 noninstitutionalized US adults aged $\geq 70$ years by selected baseline characteristics: the Second Longitudinal Study of Aging, 1994-2006

\begin{tabular}{|c|c|c|c|c|c|}
\hline $\begin{array}{l}\text { Baseline } \\
\text { characteristic }\end{array}$ & $\begin{array}{l}\text { Number } \\
\text { of deaths }\end{array}$ & $\begin{array}{l}\text { Cumulative } \\
\text { incidence, } \%(95 \% \mathrm{Cl})\end{array}$ & $\begin{array}{l}\text { Incidence per I,000 } \\
\text { person-years, } \%(95 \% \mathrm{Cl})\end{array}$ & $\begin{array}{l}\text { Model Ia } \\
\text { RR }(95 \% \mathrm{CI})\end{array}$ & $\begin{array}{l}\text { Model } 2^{\mathrm{b}} \\
\operatorname{RR}(95 \% \mathrm{Cl})\end{array}$ \\
\hline Total & 5,790 & $61.4(60.1-62.6)$ & $76.4(74.2-78.6)$ & & \\
\hline \multicolumn{6}{|l|}{ Sex } \\
\hline Men & 2,486 & $65.8(64.2-67.4)$ & $86.9(83.4-90.4)$ & $1.14(1.10-1.18)$ & $1.15(1.11-1.19)$ \\
\hline Women & 3,304 & $58.4(56.9-59.9)$ & $70.0(67.5-72.5)$ & I.0 (referent) & 1.0 (referent) \\
\hline \multicolumn{6}{|l|}{ Age, years } \\
\hline 70-74 & $\mathrm{I}, 607$ & $44.2(42.2-46.2)$ & $47.7(45.0-50.3)$ & I.0 (referent) & I.0 (referent) \\
\hline $75-79$ & 1,662 & $60.7(58.8-62.6)$ & 73.9 (70.4-77.3) & I.42 (I.34-I.49) & I.34 (I.28-I.4I) \\
\hline$\geq 80$ & 2,521 & $83.7(82.4-84.9)$ & | 32.7 (| 28.2-|37.2) & $1.98(1.89-2.08)$ & I.79 (I.7I-I.87) \\
\hline \multicolumn{6}{|l|}{ Race/ethnicity } \\
\hline White & 5,026 & $61.3(60.0-62.6)$ & $76.2(73.9-78.5)$ & I.0 (referent) & I.0 (referent) \\
\hline Nonwhite & 764 & $62.1(59.0-65.2)$ & $78.3(72.4-84.1)$ & $1.03(0.98-1.08)$ & $0.97(0.92-1.03)$ \\
\hline \multicolumn{6}{|l|}{ Smoking status } \\
\hline Never smoked & 2,855 & $58.2(56.6-59.8)$ & $69.4(66.6-72.1)$ & I.0 (referent) & I.0 (referent) \\
\hline Former smoker & 2,158 & $62.8(61.0-64.6)$ & $80.4(76.9-84.0)$ & I.II (I.07-I.I5) & $1.08(1.04-1.13)$ \\
\hline Current smoker & 663 & $72.0(68.9-75.0)$ & $100.1(92.8-107.5)$ & 1.34 (I.28-1.40) & $1.29(1.22-1.36)$ \\
\hline \multicolumn{6}{|c|}{ Stage of ADL limitations ${ }^{c}$} \\
\hline 0 & 3,612 & $53.9(52.4-55.4)$ & $61.4(59.1-63.7)$ & I.0 (referent) & I.0 (referent) \\
\hline I & $\mathrm{I}, 179$ & 76.I (73.9-78.2) & $102.4(95.3-109.4)$ & 1.34 (1.29-1.39) & $1.20(1.15-1.25)$ \\
\hline II & 562 & $82.7(79.3-86.1)$ & $129.1(121.0-137.3)$ & $1.42(1.35-1.50)$ & $1.22(1.13-1.32)$ \\
\hline III or IV & 420 & $87.4(84.5-90.3)$ & I75.I (16I.6-188.6) & $1.50(1.43-1.58)$ & $1.20(1.10-1.30)$ \\
\hline \multicolumn{6}{|c|}{ Stage of IADL limitations ${ }^{d}$} \\
\hline 0 & 2,596 & $49.9(48.3-51.5)$ & $59.9(57.7-62.1)$ & I.0 (referent) & I.0 (referent) \\
\hline I & 1,352 & $68.6(66.5-70.8)$ & 85.8 (79.7-91.8) & 1.27 (1.22-1.32) & $1.14(1.10-1.19)$ \\
\hline II & 862 & $77.5(74.8-80.1)$ & $129.0(|2| .|-| 36.9)$ & 1.39 (I.33-1.46) & 1.21 (1.14-I.28) \\
\hline III or IV & 645 & 88.1 (85.7-90.6) & $196.6(|8| .|-2| 2.2)$ & $1.58(1.50-1.66)$ & $1.36(1.28-1.46)$ \\
\hline \multicolumn{6}{|l|}{ Social activity ${ }^{\mathrm{e}}$} \\
\hline Low (0-3) & 1,949 & $75.9(74.0-77.9)$ & 115.7 (II $0.3-121.0)$ & 1.36 (1.30-1.43) & 1.21 (I.I5-I.27) \\
\hline Medium (4-5) & 2,282 & $62.4(60.6-64.2)$ & $77.5(74.2-80.9)$ & 1.17 (1.12-1.22) & $1.10(1.05-1.14)$ \\
\hline High (6-7) & $\mathrm{I}, 559$ & $48.9(46.9-50.9)$ & $53.5(50.8-56.3)$ & 1.0 (referent) & I.0 (referent) \\
\hline \multicolumn{6}{|l|}{ COPD status ${ }^{f}$} \\
\hline No & 5,159 & $60.4(59.1-61.7)$ & 74.I (7I.8-76.4) & I.0 (referent) & I.0 (referent) \\
\hline Yes & 631 & $70.7(67.4-74.0)$ & $102.0(93.4-110.6)$ & 1.15 (I.09-1.2I) & $1.07(1.01-1.13)$ \\
\hline
\end{tabular}

Notes: a Model I - relative risk (RR) and $95 \%$ confidence interval (Cl) obtained from multiple logistic regression models, with adjustment for age, sex, race/ethnicity, and smoking status; ${ }^{b}$ model $2-R R$ and $95 \% \mathrm{Cl}$ obtained from multiple logistic regression models that adjusted for all covariates in the table; 'stages of functional activities of daily living (ADL) limitations were based on participant's response to six questions about his/her difficulty in bathing/showering, dressing, eating, getting in or out of bed or chairs, walking, and using or getting to the toilet; 'stages of instrumental activities of daily living (IADL) limitations were based on participant's response to six questions about his/her difficulty in preparing meals, shopping, managing money, using the telephone, doing light housework, and doing heavy housework; elevel of social activity was derived from a social activities index score, which was based on participant's responses to multiple questions about his/her participation in the following activities during the previous 2 weeks - getting together with friends or neighbors; talking on the telephone with friends or neighbors; getting together with relatives; talking on the telephone with relatives; going to church, temple, or other place of worship; going to a show or movie, sports events, club meeting, class, or other group event; or going out to eat at a restaurant; 'chronic obstructive pulmonary disease (COPD) based on self-reported diagnosis of chronic bronchitis or emphysema.

community-dwelling older adults was consistent with previous findings that physical activity limitations, including ADL limitations among people with COPD, were positively associated with mortality risk. ${ }^{15,17,26}$ However, it was not clear in the present study why the risk of mortality increased gradually at mild or moderate ADL difficulty (stage I and II) relative to no difficulty with ADL, and then reached a plateau at severe or complete ADL difficulty (stage III or IV). It is plausible that the finding might be attributable to the severity of COPD and/or unknown risk factors. The other possible explanation was that those respondents with severe or complete ADL difficulty were more likely to die at 1 and 5 years, so deaths among this group leveled off at 10 and 12 years. ${ }^{26}$ In addition, the relationship between COPD and all-cause mortality was much more modest compared to what has been described in other cohorts. ${ }^{37,38}$ This may be explained by the older age of the cohort, self-reported COPD, or lack of information about severity classification in this study.

The finding that the relationship between COPD and mortality risk was moderately attenuated but was not completely explained by stages of ADL and IADL limitations suggested that the assistance provided by caregivers to the older adults with COPD and with relatively severe activity limitations might help improve their health status. 
A

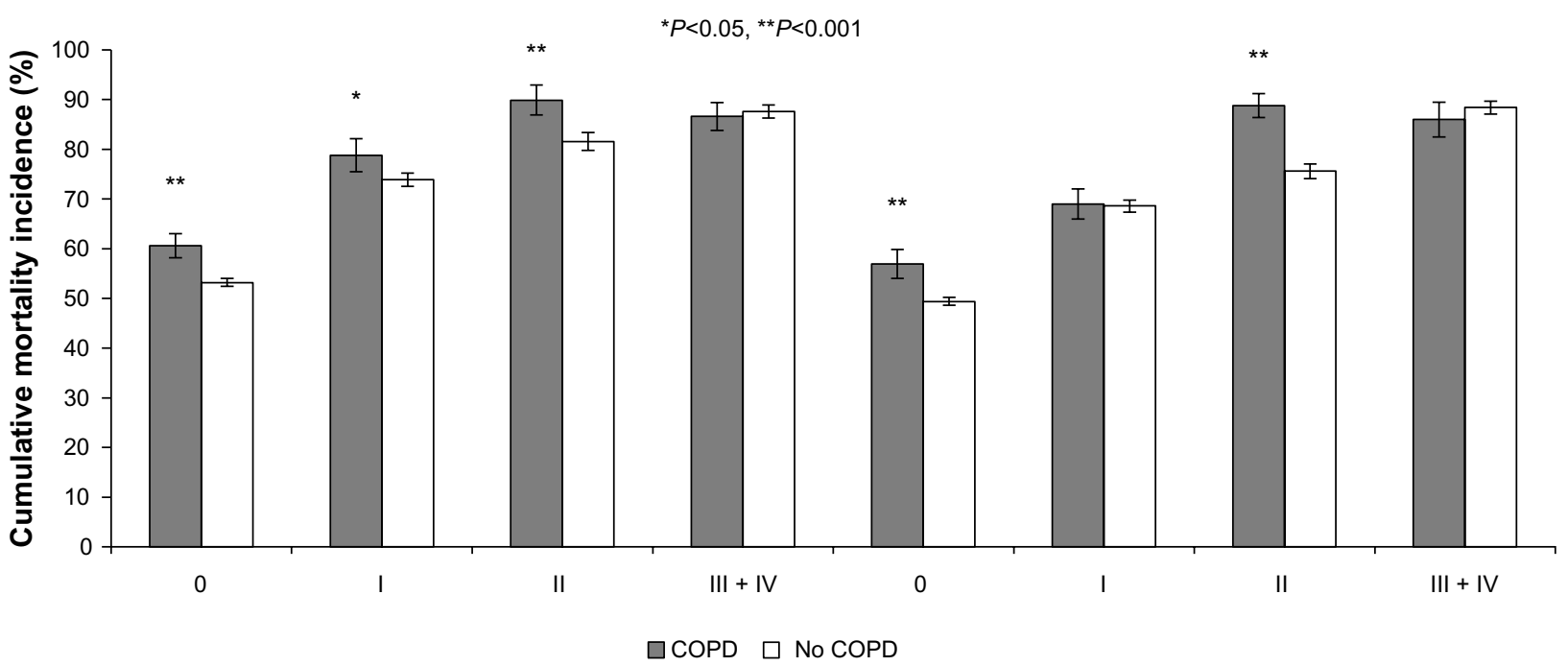

Figure 3 Cumulative mortality incidence (\%) and 95\% confidence intervals through December 31, 2006 among the Second Supplement on Aging participants, by chronic obstructive pulmonary disease (COPD) and either stage of activities of daily living limitations (A) or stage of instrumental activities of daily living limitations (B): Second Longitudinal Study on Aging, 1994-2006.

Although we found that respondents with COPD were less likely to report engaging in social activities than those without COPD, nearly two-thirds of all respondents had a low or medium score in social activity. Results from previous studies have shown that people with COPD were more likely to report being lonely and less likely to report engaging in social activities because of ADL or IADL difficulties. ${ }^{39}$ Such a negative association between level of social activities and mortality risk was consistent with previous findings that mortality risk could be reduced by increased participation in social activities. ${ }^{40-42}$ However, research on social engagement has shown that its relationship with mortality was complex and could impact health through various channels, such as influencing health behavior, improving psychological conditions, and altering physiologic states. ${ }^{43}$

This study is subject to the following limitations, although our findings could be generalizable to the national noninstitutionalized adult population aged 70 years or older. First, self-reported COPD prevalence in the NHIS data may be underestimated and have influenced our results. However, results of a previous study based on data from the Nurses' Health Study (1988-1996), in which 78\% of self-reported COPD cases were validated using objective clinical measures, indicated that self-reported surveys could provide reliable estimates for COPD studies. ${ }^{44}$ Second, the subjective measure of activity limitations used in this study have not been validated. Results from at least one previous study suggest that objective measures of physical functioning might be more sensitive in predicting a preclinical disability than subjective measures, such as self-reported difficulties with ADL and IADL. ${ }^{45}$ Results from a more recent study, however, indicated that analyses based on subjective measures of difficulties with daily activities and those based on objective measures of such activities had similar power to predict risk for subsequent disability. ${ }^{46}$ In addition, results from another recent study suggest that estimates of selfreported ADL limitations were comparable to those based on the BODE index (which is calculated from clinical measurements of body mass index, airflow obstruction, dyspnea, and exercise capacity). ${ }^{47}$ Finally, because of the cross-sectional design of SOA II, we could not determine the causal direction of the associations we found between COPD and ADL and IADL limitations.

\section{Conclusion}

COPD is positively associated with disability and mortality risk among US adults aged 70 years or older. These findings support current efforts to develop effective strategies to mitigate the impact of disability among older adults. For example, there are several effective disease-management and physical activity interventions shown to reduce the progression of functional decline among older adults. ${ }^{19}$ The challenge will be to expand their reach and determine how to translate such efforts into practice. In addition, our finding that the excess COPD-mortality relationship was moderately attenuated by stages of ADL and IADL limitations suggests that interventions to improve physical 
functioning among COPD patients with relatively high levels of activity limitations might reduce their risks related to the progression of COPD.

\section{Author contributions}

Yong Liu and Janet B Croft developed the conceptual model. Yong Liu performed all statistical analyses and wrote the paper under the direction of Janet B Croft. Lynda A Anderson and Anne $\mathrm{G}$ Wheaton contributed to interpretation of the data and critical revision of the manuscript for important public health content. Letitia R Presley-Cantrell and Earl S Ford contributed to critical revision of the manuscript. All authors made significant contributions to data generation/analysis, writing or revising of the manuscript, and gave their final approval of the proof to be published.

\section{Disclosure}

The authors report no conflicts of interest in this work. The findings and conclusions in this report are those of the authors, and do not necessarily represent the official position of the Centers for Disease Control and Prevention.

\section{References}

1. Kochanek KD, Xu JQ, Murphy SL, Miniño AM, Kung HC. Deaths: final data for 2009. National Vital Stat Rep. 2011;60:1-51.

2. Murphy SL, Xu JQ, Kochanek KD. Deaths: preliminary data for 2010. National Vital Stat Rep. 2013;61:1-52.

3. Celli BR, MacNee W. Standards for the diagnosis and treatment of patients with COPD: summary of the ATS/ERS position paper. Eur Respir. 2004;23:932-946.

4. Centers for Disease Control and Prevention (CDC). Deaths from chronic obstructive pulmonary disease-United States - 2000-2005. MMWR Morb Mortal Wkly Rep. 2008;57:1229-1232.

5. American Lung Association. Trends in tobacco use. 2011. Available from: http://www.lung.org/finding-cures/our-research/trend-reports/ Tobacco-Trend-Report.pdf. Accessed November 4, 2013.

6. Jemal A, Ward E, Hao Y, Thun M. Trends in the leading causes of death in the United States, 1970-2002. JAMA. 2005;294:1255-1259.

7. Ford ES, Mannino DM, Zhao G, Li C, Croft JB. Changes in mortality among US adults with COPD in two national cohorts recruited from 1971-1975 and 1988-1994. Chest. 2012;141:101-110.

8. Global Initiative for Chronic Obstructive Lung Disease. Global strategy for the diagnosis, management and prevention of chronic obstructive pulmonary disease. 2011. Available from: http://www.goldcopd. org/uploads/users/files/GOLD_Report_2011_Feb21.pdf. Accessed November 4, 2013.

9. Dudley DL, Glaser EM, Jorgenson BN, Logan DL. Psychosocial concomitants to rehabilitation in chronic obstructive pulmonary disease. Part 1: Psychosocial and psychological considerations. Chest. 1980;77:413-420.

10. Kanervisto M, Saarelainen S, Vasankari T, et al. COPD, chronic bronchitis and capacity for day-to-day activities: negative impact of illness on health-related quality of life. Chron Respir Dis. 2010;7: 207-215.

11. Gift A, McCrone S. Depression in patients with COPD. Heart Lung. 1993;22:289-297.
12. Penninx BW, van Tilburg T, Kriegsman DM, Boeke AJ, Deeg DJ, van Eijk JT. Social network, social support, and loneliness in older persons with different chronic diseases. J Aging Health. 1999;11:151-168.

13. Rolland JS. Chronic illness and the life cycle: a conceptual framework. Fam Process. 1987;26:203-221.

14. Donaldson GC, Wilkinson TM, Hurst JR, Perera WR, Wedzicha JA. Exacerbations and time spent outdoors in chronic obstructive pulmonary disease. Am J Respir Crit Care Med. 2005;171:446-452.

15. Garcia-Aymerich J, Lange P, Benet M, Schnohr P, Antó JM. Regular physical activity reduces hospital admission and mortality in chronic obstructive pulmonary disease: a population based cohort study. Thorax. 2006;61:772-778

16. Pitta F, Troosters T, Probst VS, Spruit MA, Decramer M, Gosselink R. Physical activity and hospitalization for exacerbation of COPD. Chest. 2006;129;536-544.

17. Martinez F, Foster G, Curtis JL, et al. Predictors of mortality in patients with emphysema and severe airflow obstruction. Am J Respir Crit Care Med. 2006;173:1326-1334.

18. Respiratory Diseases. HealthyPeople.gov [webpage on the Internet]. Available from: http://www.healthypeople.gov/2020/topicsobjectives2020/ objectiveslist.aspx?topicId=36. Accessed November 13, 2013.

19. Branch LG, Meng H, Guralnik JM. Disability and functional status. In: Prohaska T, Anderson LA, Binstock R, editors. Public Health for an Aging Society. Baltimore: Johns Hopkins University Press; 2012.

20. Katz S, Ford AB, Moskowitz RW, Jackson BA, Jaffe MW. Studies of illness in the aged. The index of ADL: a standardized measure of biological and psychosocial function. JAMA. 1963;185:914-919.

21. Katz S. Assessing self-maintenance: activities of daily living, mobility, and instrumental activities of daily living. J Am Geriatr Soc. 1983;31: 721-727.

22. Lawton MP, Brody E. Assessment of older people: self-maintaining and instrumental activities of daily living. Gerontologist. 1969;9: 179-186.

23. Massey JT, Moore TF, Parsons VL, Tadros W. Design and estimation for the National Health Interview Survey, 1985-1994. National Center for Health Statistics. Vital Health Stat 2. 1989;110.

24. Stineman MG, Xie D, Pan Q, Kurichi JE, Saliba D, Streim J. Activity of daily living staging, chronic health conditions, and perceived lack of home accessibility features for elderly people living in the community. J Am Geriatr Soc. 2011;59:454-462.

25. Stineman MG, Henry-Sánchez JT, Kurichi JE, et al. Staging activity limitation and participation restriction in elderly community-dwelling persons according to difficulties in self-care and domestic life functioning. Am J Phys Med Rehabil. 2012;91:126-140.

26. Stineman MG, Xie D, Pan Q, et al. All-cause 1-, 5-, and 10-year mortality in elderly people according to activities of daily living stage. J Am Geriatr Soc. 2012;60:485-492.

27. LSOA II Public-use Linked Mortality File (2006). Centers for Disease Control and Prevention [webpage on the Internet]. Available from: http:// www.cdc.gov/nchs/data_access/data_linkage/mortality/lsoaii_linkage. htm. Accessed November 13, 2013.

28. World Health Organization. International classification of functioning, disability and health (ICF). 2001. Available from: http://www.who.int/ classifications/icf/en. Accessed November 4, 2013.

29. Stineman MG, Ross RN, Fiedler R, Granger CV, Maislin G. Functional independence staging: conceptual foundation, face validity, and empirical derivation. Arch Phys Med Rehabil. 2003;84:29-37.

30. Grant MD, Piotrowsk ZH, Chappell R. Self-reported health and survival in the Longitudinal Study of Aging, 1984-1986. J Clin Epidemiol. 1995;48:375-387.

31. Zhang X, Norris SL, Gregg EW, Beckles G. Social support and mortality among older persons with diabetes. Diabetes Educ. 2007;33: 273-281.

32. Jasti S, Dudley WN, Goldwater E. SAS macros for testing statistical mediation in data with binary mediators or outcomes. Nurs Res. 2008;57:118-122. 
33. MacKinnon DP, Dwyer JH. Estimating mediated effects in prevention studies. Eval Rev. 1993;17:144-158.

34. Baron RM, Kenny DA. The moderator-mediator variable distinction in social psychological research: conceptual, strategic, and statistical considerations. J Pers Soc Psychol. 1986;51:1173-1182.

35. Celli BR, Rassulo J, Make B. Dyssynchronous breathing associated with arm but not leg exercise in patients with COPD. $N$ Engl J Med. 1986;314:1485-1490.

36. Vermeulen J, Neyens JC, van Rossum E, Spreeuwenberg MD, de Witte LP. Predicting ADL disability in community-dwelling elderly people using physical frailty indicators: a systematic review. BMC Geriatr. 2011:11:33.

37. Mannino DM, Buist AS, Petty TL, Enright PL, Redd SC. Lung function and mortality in the United States: data from the First National Health and Nutrition Examination Survey follow up study. Thorax. 2003;58: 388-393.

38. Mannino DM, Doherty DE, Buist AS. Global Initiative on Obstructive Lung Disease (GOLD) classification of lung disease and mortality: findings from the Atherosclerosis Risk in Communities (ARIC) study. Respir Med. 2006;100:115-122.

39. Kara M, Mirici A. Loneliness, depression, and social support of Turkish patients with chronic obstructive pulmonary disease and their spouses. J Nur Scholarsh. 2004;36:331-336.

40. Berkman LF, Syme SL. Social networks, host resistance, and mortality: a nine-year follow-up study of Alameda County residents. Am J Epidemiol. 1979;109:186-204.
41. House JS, Robbins C, Metzner HL. The association of social relationships and activities with mortality: prospective evidence from the Tecumseh community health study. Am J Epidemiol. 1982;116:123-140.

42. Schoenbach VJ, Kaplan BH, Fredman L, Kleinbaum DG. Social ties and mortality in Evans County, Georgia. Am J Epidemiol. 1986;123: $577-591$.

43. Morrow-Howell N, Gehlert S. Social engagement and a healthy aging society. In: Prohaska T, Anderson LA, Binstock R, editors. Public Health for an Aging Society. Baltimore: Johns Hopkins University Press; 2012.

44. Barr RG, Herbstman J, Speizer FE, Camargo CA Jr. Validation of selfreported chronic obstructive pulmonary disease in a cohort study of nurses. Am J Epidemiol. 2002;155:965-971.

45. Rozzini R, Frisoni GB, Ferrucci L, Barbisoni P, Bertozzi B, Trabucchi M. The effect of chronic diseases on physical function. Comparison between activities of daily living scales and the Physical Performance Test. Age Ageing. 1997;26:281-287.

46. Shah RC, Buchman AS, Leurgans S, Boyle PA, Bennett DA. Association of total daily physical activity with disability in community-dwelling older persons: a prospective cohort study. BMC Geriatr. 2012;23:63.

47. Simon KM, Carpes MF, Corrêa KS, dos Santos K, Karloh M, Mayer AF. Relationship between daily living activities (ADL) limitation and the BODE index in patients with chronic obstructive pulmonary disease. Rev Bras Fisioter. 2011;15:212-218.
International Journal of COPD

\section{Publish your work in this journal}

The International Journal of COPD is an international, peer-reviewed journal of therapeutics and pharmacology focusing on concise rapid reporting of clinical studies and reviews in COPD. Special focus is given to the pathophysiological processes underlying the disease, intervention programs, patient focused education, and self management protocols.

\section{Dovepress}

This journal is indexed on PubMed Central, MedLine and CAS. The manuscript management system is completely online and includes a very quick and fair peer-review system, which is all easy to use. Visit http://www.dovepress.com/testimonials.php to read real quotes from published authors. 